\title{
OPTIMAL RETAILER'S INVENTORY POLICY UNDER SUPPLIER CREDITS LINKED TO RETAILER PAYMENT TIME
}

\author{
Yung-Fu Huang ${ }^{1}$ and Kuang-Hua $\mathrm{Hsu}^{2}$ \\ ${ }^{1}$ Department of Business Administration, Chaoyang University of Technology, \\ Taichung, Taiwan, R.O.C.huf@cyut.edu.tw \\ ${ }^{2}$ Department of Finance, Chaoyang University of Technology, \\ Taichung, Taiwan, R.O.C. khhsu@mail.cyut.edu.tw
}

\begin{abstract}
This paper wants to investigate the retailer's optimal cycle time and optimal payment time under supplier credits including conditionally permissible delay in payments and cash discount depending on retailer payment time. That is, the retailer can obtain fully permissible delay in payments and cash discount if the payment is paid before the period of full delay payments permitted by the supplier. Otherwise, the retailer will just obtain partially permissible delay in payments within the period of partial delay payments permitted by the supplier. The supplier uses this policy to attract retailer to pay the payment as soon as possible to shorten the collection period. One theorem is developed to efficiently determine the optimal replenishment and payment policy for the retailer.
\end{abstract}

Keywords- Inventory, Optimization, Permissible delay in payment, Cash discount

\section{INTRODUCTION}

The traditional EOQ (Economic Order Quantity) model assumes the payment for the quantity ordered is made when the quantity is received. However, in practice it is found that supplier allows a certain fixed credit period to the retailer to promote his/her commodities. The effect of supplier credit policy on inventory problem has received the attention of many researchers. Goyal [7] established a single-item inventory model under permissible delay in payments. Chung [4] developed an alternative approach to determine the economic order quantity under condition of permissible delay in payments. Aggarwal and Jaggi [1] considered the inventory model with an exponential deterioration rate under the condition of permissible delay in payments. Teng [12] assumed that the selling price not equal to the purchasing price to modify Goyal's model [7]. Huang [8] extended this issue under two levels of trade credit and developed an efficient solution-finding procedure to determine the optimal lot-sizing policy of the retailer. Chung and Huang [5] investigated this issue within EPQ framework and developed an efficient solution-finding procedure to determine the optimal cycle time for the retailer. Chang et al. [3] and Chung and Liao [6] deal with the problem of determining the economic order quantity for exponentially deteriorating items under permissible delay in payments depending on the ordering quantity. Huang [9] investigated that the unit selling price and the unit purchasing price are not necessarily equal within the EPQ framework under supplier's trade credit policy.

The timing of cash flows of an investment proposal is important because the sooner the money becomes available, the sooner it can be used for other worthwhile purposes. Therefore, it makes economic sense for the retailer to delay the settlement of the 
replenishment account up to the last moment of the permissible delay period allowed by the supplier. From the viewpoint of the supplier, the supplier hopes that the payment is paid from retailer as soon as possible. It can avoid the possibility of resulting in bad debt. Recently, Chang [2], Ouyang et al. [11] and Huang and Chung [10] investigated the inventory policy under cash discount and trade credit.

What the above statement describes is just one of ways of attracting the retailer to pay the payment as soon as possible. This paper tries to develop another more effective supplier's credit policy to shorten the collection period. We assume that the retailer can obtain fully permissible delay in payments and cash discount if the payment is paid before the period of full delay payments permitted by the supplier. Otherwise, the retailer will just obtain partially permissible delay in payments within the period of partial delay payments permitted by the supplier. In the policy of partial delay payments, the retailer must make partial payment at the time the retailer places a replenishment order and the rest of the total amount is payable before or at the end of the permissible credit period. The supplier uses the credits policy depending on payment time to attract the retailer to pay the payment as soon as possible to shorten the collection period. Under this condition, we model the retailer's inventory system as a cost minimization problem and prove one theorem to efficiently determine the retailer's optimal replenishment and optimal payment policy.

\section{MODEL FORMULATION}

\subsection{Notation:}

$D=$ demand rate per year

$A=$ cost of placing one order

$c=$ unit purchasing price

$h=$ unit stock holding cost per year excluding interest charges

$r=$ cash discount rate, $0 \leq r<1$

$\alpha=$ the fraction of the total amount owed payable at the time of placing an order, $0 \leq \alpha \leq 1$

$I_{e}=$ interest earned per $\$$ per year

$I_{k}=$ interest charges per $\$$ investment in inventory per year

$M_{1}=$ the period of full delay payments permitted in years

$M_{2}=$ the period of partial delay payments permitted in years, $M_{1}<M_{2}$

$T=$ the cycle time in years

$T R C(T)=$ the annual total relevant cost when $T>0$

$$
= \begin{cases}T R C_{1}(T) & \text { if the payment is paid at time } M_{1} \\ T R C_{2}(T) & \text { if the payment is paid at time } M_{2}\end{cases}
$$

$T_{1} *=$ the optimal cycle time of $T R C_{1}(T)$

$T_{2}{ }^{*}=$ the optimal cycle time of $T R C_{2}(T)$

$T^{*}=$ the optimal cycle time of $T R C(T)$

$Q^{*}=$ the optimal order quantity $=D T^{*}$.

\subsection{Assumptions:}

(1) Demand rate is known and constant.

(2) Shortages are not allowed.

(3) Time horizon is infinite. 
(4) Replenishments are instantaneous.

(5) $I_{k} \geq I_{e}$.

(6) Supplier offers a cash discount and fully delayed payment to the retailer if payment is paid within $M_{1}$, otherwise just partially delayed payment if payment is paid within $M_{2}$.

(7) If payment is paid within $M_{1}$, when the account is settled the retailer starts paying for the interest charges on the items in stock. If payment is paid behind $M_{1}$ but within $M_{2}$, as the order is received, the retailer must make a partial payment $a c D T$ to the supplier. Then the retailer must pay off the remaining balance $(1-\alpha) c D T$ at the end of the partially permissible delay period $M_{2}$.

(8) During the time the account is not settled, generated sales revenue is deposited in an interest-bearing account.

\subsection{The model:}

The annual total relevant cost consists of the following elements.

(1) Annual ordering cost $=A / T$.

(2) Annual stock holding cost (excluding interest charges) $=D T H / 2$.

(3) Annual purchasing cost:

Since the supplier offers a cash discount if payment is paid within $M_{1}$, there are two payment policies for the retailer.

Case 1 : Payment is paid at time $M_{1}$, the annual purchasing cost $=c(1-r) D$.

Case 2 : Payment is paid at time $M_{2}$, the annual purchasing cost $=c D$.

(4) Cost of interest charges for the items kept in stock per year:

Case 1: Payment is paid at time $M_{1}$, according to assumption (7); there are two sub-cases in terms of interests charged per year.

Case 1.1: $T \geq M_{1}$.

Annual interests payable $=c(1-r) I_{k} D\left(T-M_{1}\right)^{2} / 2 T$.

Case 1.2: $T \leq M_{1}$

In this case, annual interests payable $=0$.

Case 2: Payment is paid at time $M_{2}$, according to assumption (7); there are three sub-cases in terms of interests charged per year.

Case 2.1: $\frac{M_{2}}{\alpha} \leq T$, as shown in Figure 1 .

Annual interests payable $=c I_{k}\left[D T^{2} / 2-(1-\alpha) D T M_{2}\right] / T$.

Case 2.2: $M_{2} \leq T \leq \frac{M_{2}}{\alpha}$, as shown in Figure 2 .

Annual interests payable $=c I_{k}\left[\alpha^{2} D T^{2}+D\left(T-M_{2}\right)^{2}\right] / 2 T$.

Case 2.3: $T \leq M_{2}$, as shown in Figure 3.

Annual interests payable $=c I_{k} \alpha^{2} D T^{2} / 2 T$. 


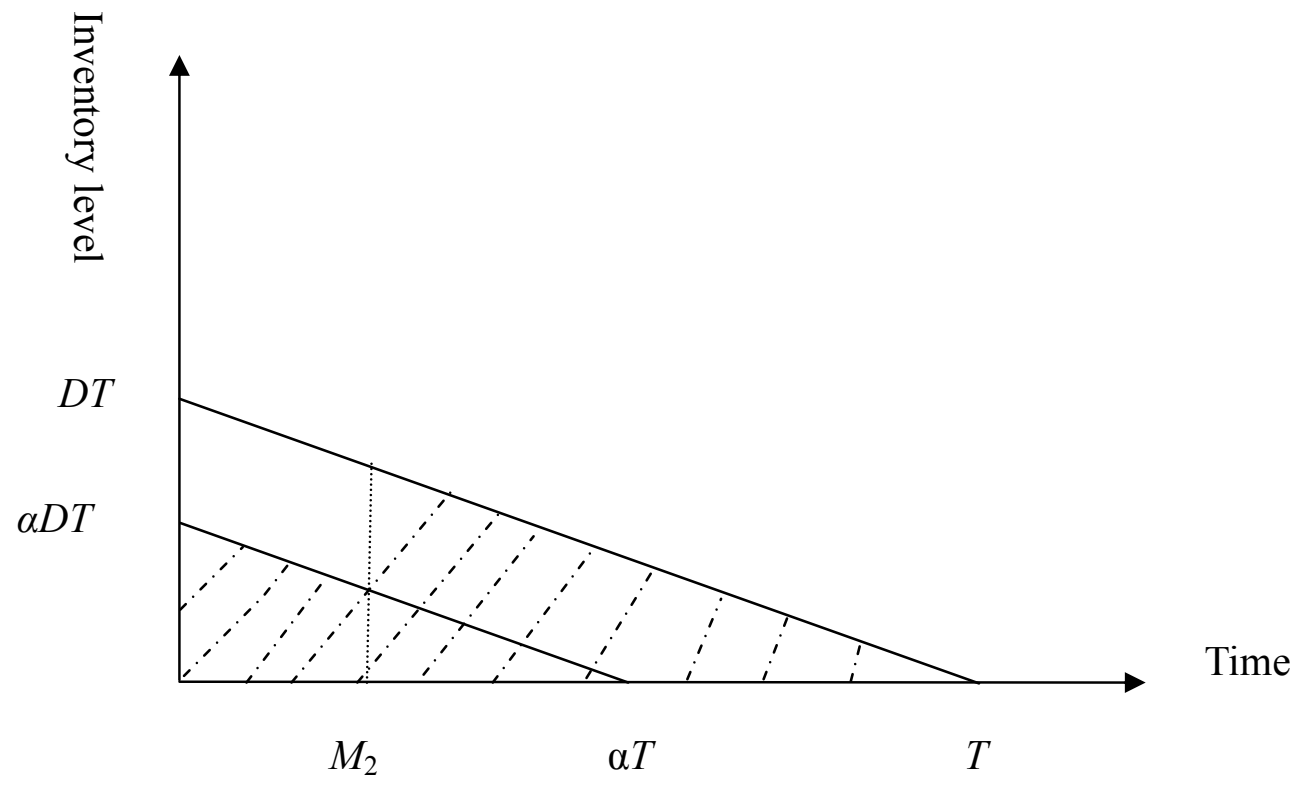

Figure 1. The inventory level and the total amount of interest payable when $M_{2} / \alpha \leq T$

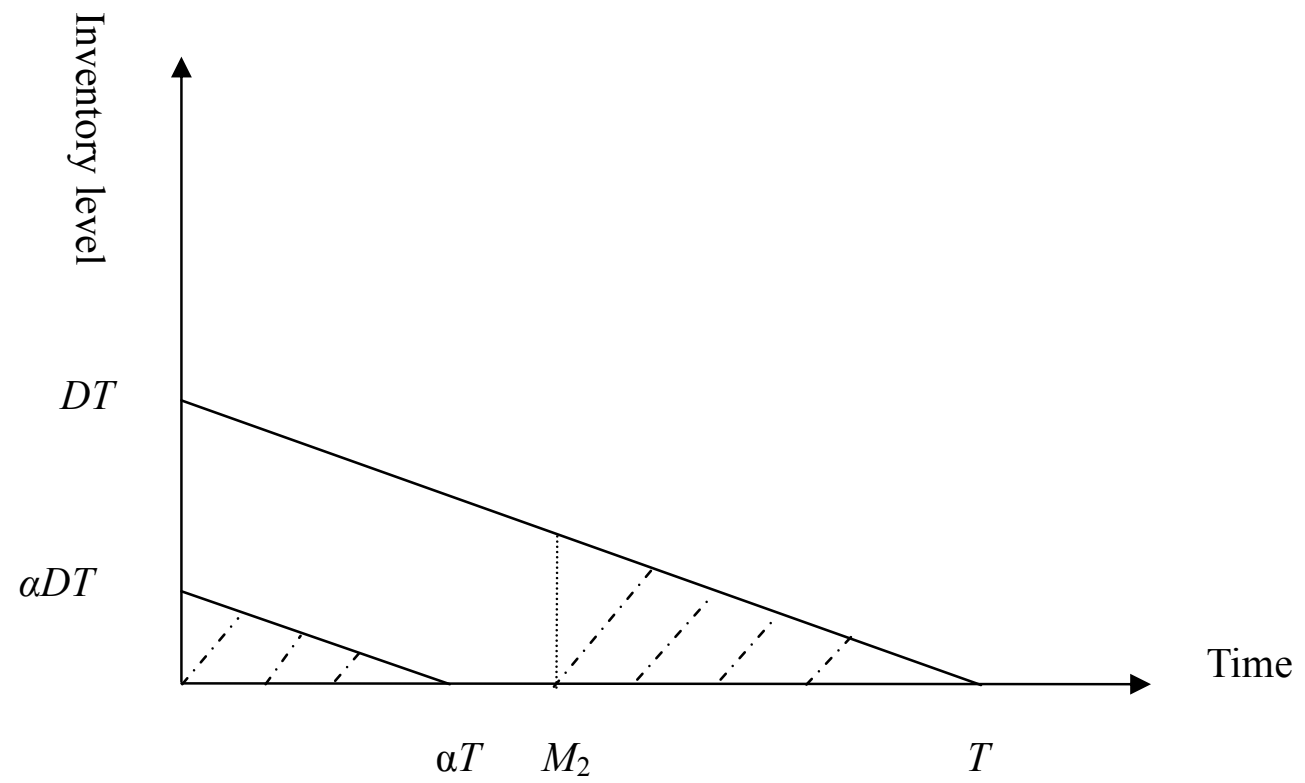

Figure 2. The inventory level and the total amount of interest payable when $M_{2} \leq T \leq M_{2} / \alpha$ 


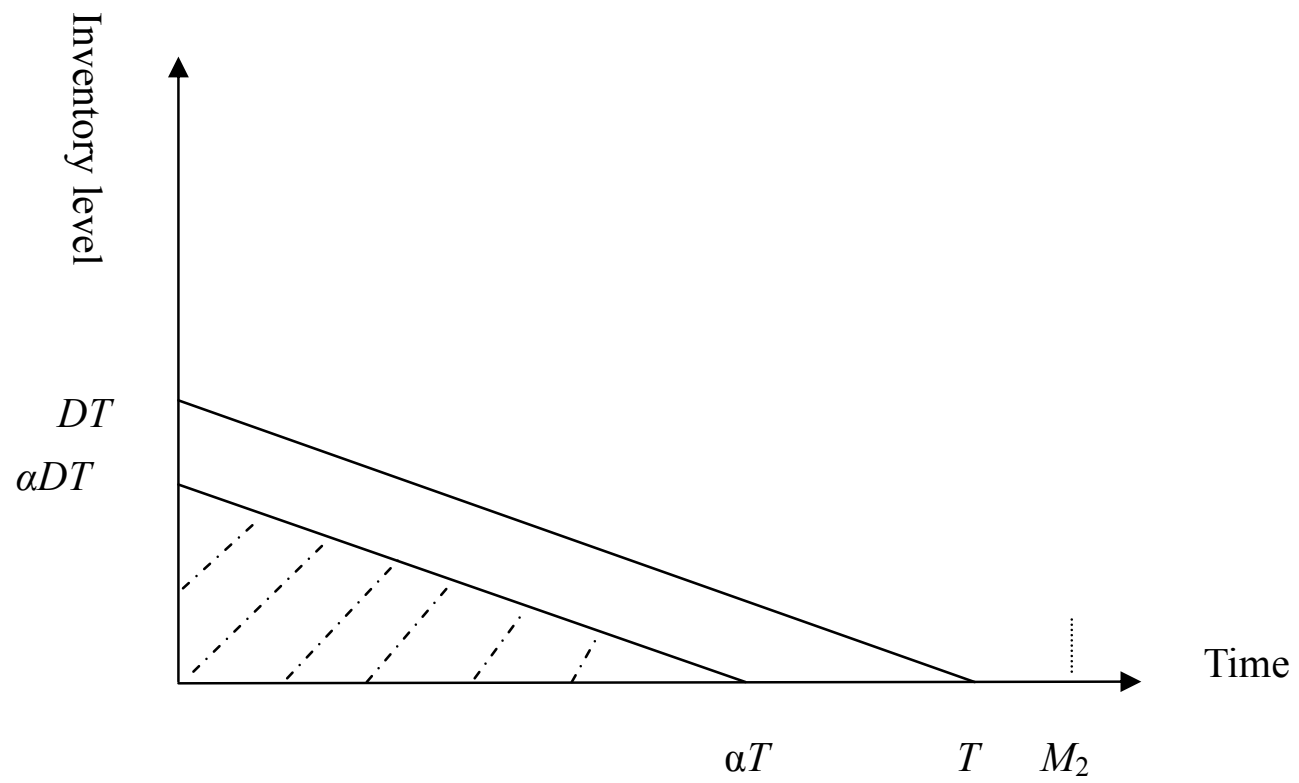

Figure 3. The inventory level and the total amount of interest payable when $0<T \leq M_{2}$

(5) Interests earned per year:

Case 1: Payment is paid at time $M_{1}$, according to assumption (8); there are two sub-cases in terms of interests earned per year.

Case $1.1 T \geq M_{1}$.

Interests earned per year $=c I_{e} D M_{1}^{2} / 2 T$.

Case $1.2 T \leq M_{1}$.

Interests earned per year $=c I_{e}\left[D T^{2} / 2+D T\left(M_{1}-T\right)\right] / T=c I_{e} D T\left(M_{1}-T / 2\right) / T$.

Case 2: Payment is paid at time $M_{2}$, according to assumption (8); there are two sub-cases in terms of interests earned per year.

Case $2.1 T \geq M_{2}$.

Interests earned per year $=c I_{e} D M_{2}^{2} / 2 T$.

Case 2.2 $T \leq M_{2}$

Interests earned per year $=c I_{e}\left[D T^{2} / 2+D T\left(M_{2}-T\right)\right] / T=c I_{e} D T\left(M_{2}-T / 2\right) / T$.

From the above arguments, the annual total relevant cost for the retailer can be expressed as:

Annual total relevant $\operatorname{cost}=$ ordering cost + stock-holding cost + purchasing cost + interest payable - interest earned.

We show that the annual total relevant cost is given by

Case 1: Payment is paid at time $M_{1}$

$$
T R C_{1}(T)=\left\{\begin{array}{llr}
T R C_{11}(T) & \text { if } & T \geq M_{1} \\
T R C_{12}(T) & \text { if } & 0<T \leq M_{1}
\end{array}\right.
$$

where 
and

$$
T R C_{11}(T)=\frac{A}{T}+\frac{D T h}{2}+c(1-r) D+\frac{c(1-r) I_{k} D\left(T-M_{1}\right)^{2}}{2 T}-\frac{c I_{e} D M_{1}^{2}}{2 T}
$$

$$
T R C_{12}(T)=\frac{A}{T}+\frac{D T h}{2}+c(1-r) D-D c I_{e}\left(M_{1}-\frac{T}{2}\right) .
$$

At $T=M_{1}$, we find $T R C_{11}\left(M_{1}\right)=T R C_{12}\left(M_{1}\right)$. Hence $T R C_{1}(T)$ is continuous and well-defined. All $T R C_{11}(T), T R C_{12}(T)$ and $T R C_{1}(T)$ are defined on $T>0$.

Case 2: Payment is paid at time $M_{2}$

$$
T R C_{2}(T)=\left\{\begin{array}{llr}
T R C_{21}(T) & \text { if } & T \geq \frac{M_{2}}{\alpha} \\
T R C_{22}(T) & \text { if } & M_{2} \leq T \leq \frac{M_{2}}{\alpha} \\
T R C_{23}(T) & \text { if } & 0<T \leq M_{2}
\end{array}\right.
$$

where

$$
\begin{aligned}
& T R C_{21}(T)=\frac{A}{T}+\frac{D T h}{2}+c D+c I_{k} D T\left[\frac{T}{2}-(1-\alpha) M_{2}\right] / T-c I_{e} D M_{2}^{2} / 2 T \\
& T R C_{22}(T)=\frac{A}{T}+\frac{D T h}{2}+c D+c I_{k} D\left[\alpha^{2} T^{2}+\left(T-M_{2}\right)^{2}\right] / 2 T-c I_{e} D M_{2}^{2} / 2 T
\end{aligned}
$$

and

$$
T R C_{23}(T)=\frac{A}{T}+\frac{D T h}{2}+c D+\alpha^{2} c I_{k} D T^{2} / 2 T-c I_{e} D T\left(M_{2}-\frac{T}{2}\right) / T .
$$

Since $T R C_{21}\left(\frac{M_{2}}{\alpha}\right)=T R C_{22}\left(\frac{M_{2}}{\alpha}\right)$ and $T R C_{22}\left(M_{2}\right)=T V C_{23}\left(M_{2}\right), \operatorname{TRC}(T)$ is continuous and well-defined. All $T R C_{21}(T), T R C_{22}(T), T R C_{23}(T)$ and $T R C_{2}(T)$ are defined on $T>0$.

\subsection{Optimality conditions:}

From equations (2)-(3) and (5)-(7) yield

$$
\begin{aligned}
& \operatorname{TRC}_{11}{ }^{\prime}(T)=\frac{-\left\{2 A+c D M_{1}^{2}\left[(1-r) I_{k}-I_{e}\right]\right\}}{2 T^{2}}+\frac{D\left[h+c(1-r) I_{k}\right]}{2}, \\
& T R C_{11}^{\prime \prime}(T)=\frac{2 A+c D M_{1}^{2}\left[(1-r) I_{k}-I_{e}\right]}{T^{3}}, \\
& T R C_{12}^{\prime}{ }^{\prime}(T)=\frac{-A}{T^{2}}+\frac{D\left(h+c I_{e}\right)}{2}, \\
& T R C_{12}^{\prime \prime}(T)=\frac{2 A}{T^{3}}>0, \\
& T R C_{21}{ }^{\prime}(T)=\frac{-\left(2 A-c D M_{2}^{2} I_{e}\right)}{2 T^{2}}+\frac{D\left(h+c I_{k}\right)}{2} \\
& T R C_{21}{ }^{\prime \prime}(T)=\frac{2 A-c D M_{2}^{2} I_{e}}{T^{3}}
\end{aligned}
$$




$$
\begin{aligned}
& T R C_{22}{ }^{\prime}(T)=\frac{-\left[2 A+c D M_{2}{ }^{2}\left(I_{k}-I_{e}\right)\right]}{2 T^{2}}+\frac{D\left[h+c I_{k}(1+\alpha)^{2}\right]}{2}, \\
& T R C_{22}{ }^{\prime \prime}(T)=\frac{2 A+c D M_{2}{ }^{2}\left(I_{k}-I_{e}\right)}{T^{3}}>0, \\
& T R C_{23}{ }^{\prime}(T)=-\frac{A}{T^{2}}+\frac{D\left[h+c\left(\alpha^{2} I_{k}+I_{e}\right)\right]}{2}
\end{aligned}
$$

and

$$
T R C_{23}{ }^{\prime \prime}(T)=\frac{2 A}{T^{3}}>0 .
$$

Equations (11), (15) and (17) imply that all $T R C_{12}(T), T R C_{22}(T)$ and $T R C_{23}(T)$ are convex on $T>0$. Furthermore, we have $T R C_{11}{ }^{\prime}\left(M_{1}\right)=T R C_{12}{ }^{\prime}\left(M_{1}\right)$, $T R C_{21}{ }^{\prime}\left(\frac{M_{2}}{\alpha}\right)=T R C_{22}{ }^{\prime}\left(\frac{M_{2}}{\alpha}\right)$ and $T R C_{22}{ }^{\prime}\left(M_{2}\right)=T R C_{23}{ }^{\prime}\left(M_{2}\right)$. Then we can obtain following results.

\section{Lemma 1 :}

(A) (i) If $2 A+c D M_{1}^{2}\left[(1-r) I_{k}-I_{e}\right] \leq 0$, then $T R C_{1}(T)$ is convex on $\left(0, M_{1}\right]$ and concave on $\left[M_{1}, \infty\right)$.

(ii) If $2 A+c D M_{1}^{2}\left[(1-r) I_{k}-I_{e}\right]>0$, then $T R C_{1}(T)$ is convex on $(0, \infty)$.

(B) (i) If $2 A-c D M_{2}^{2} I_{e} \leq 0$, then $T R C_{2}(T)$ is convex on $\left(0, M_{2} / \alpha\right]$ and concave on $\left[M_{2} / \alpha, \infty\right)$.

(ii) If $2 A-c D M_{2}^{2} I_{e}>0$, then $T R C_{2}(T)$ is convex on $(0, \infty)$.

\section{DECISION RULE OF THE OPTIMAL CYCLE TIME $\boldsymbol{T}^{*}$}

Let $T R C_{11}{ }^{\prime}\left(T_{11}{ }^{*}\right)=T R C_{12}{ }^{\prime}\left(T_{12}{ }^{*}\right)=T R C_{21}{ }^{\prime}\left(T_{21}{ }^{*}\right)=T R C_{22}{ }^{\prime}\left(T_{22}{ }^{*}\right)=T R C_{23}{ }^{\prime}\left(T_{23}{ }^{*}\right)=0$. We can obtain

$$
\begin{aligned}
& T_{11}^{*}=\sqrt{\frac{2 A+c D M_{1}^{2}\left[(1-r) I_{k}-I_{e}\right]}{D\left[h+c(1-r) I_{k}\right]}} \text { if } 2 A+c D M_{1}^{2}\left[(1-r) I_{k}-I_{e}\right]>0, \\
& T_{12} *=\sqrt{\frac{2 A}{D\left(h+c I_{e}\right)}}, \\
& T_{21}^{*}=\sqrt{\frac{2 A-c D M_{2}^{2} I_{e}}{D\left(h+c I_{k}\right)}} \text { if } 2 A-c D M_{2}^{2} I_{e}>0, \\
& T_{22} *=\sqrt{\frac{2 A+c D M_{2}^{2}\left(I_{k}-I_{e}\right)}{D\left[h+c I_{k}\left(1+\alpha^{2}\right)\right]}}
\end{aligned}
$$

and

$$
T_{23} *=\sqrt{\frac{2 A}{D\left[h+c\left(\alpha^{2} I_{k}+I_{e}\right)\right]}} .
$$

Equation (18) implies that the optimal value of $T$ for the case of $T \geq M_{1}$, that is $T_{11} * \geq$ 
$M_{1}$. We substitute Equation (18) into $T_{11} * \geq M_{1}$, then we can obtain the optimal value of $T$ if and only if $-2 A+D M_{1}^{2}\left(h+c I_{e}\right) \leq 0$.

Likewise, Equation (19) implies that the optimal value of $T$ for the case of $T \leq M_{1}$, that is $T_{12}{ }^{*} \leq M_{1}$. We substitute Equation (19) into $T_{12}{ }^{*} \leq M_{1}$, then we can obtain the optimal value of $T$ if and only if $-2 A+D M_{1}^{2}\left(h+c I_{e}\right) \geq 0$.

In a similar fashion, we can obain following results:

$$
\begin{aligned}
& M_{2} / \alpha \leq T_{21} * \text { if and only if }-\left(2 A-c D M_{2}^{2} I_{e}\right)+D\left(\frac{M_{2}}{\alpha}\right)^{2}\left(h+c I_{k}\right) \leq 0 . \\
& M_{2} \leq T_{22} * \leq M_{2} / \alpha \text { if and only if }-\left(2 A-c D M_{2}^{2} I_{e}\right)+D\left(\frac{M_{2}}{\alpha}\right)^{2}\left(h+c I_{k}\right) \geq 0 \text { and } \\
& \text { if and only if }-2 A+D M_{2}^{2}\left[h+c\left(\alpha^{2} I_{k}+I_{e}\right)\right] \leq 0, \\
& T_{23} * \leq M_{2} \text { if and only if }-2 A+D M_{2}^{2}\left[h+c\left(\alpha^{2} I_{k}+I_{e}\right)\right] \geq 0 .
\end{aligned}
$$

Furthermore, to simplify, we let

$$
\begin{aligned}
& \Delta_{1}=-2 A+D M_{1}^{2}\left(h+c I_{e}\right), \\
& \Delta_{2}=-\left(2 A-c D M_{2}^{2} I_{e}\right)+D\left(\frac{M_{2}}{\alpha}\right)^{2}\left(h+c I_{k}\right)
\end{aligned}
$$

and

$$
\Delta_{3}=-2 A+D M_{2}^{2}\left[h+c\left(\alpha^{2} I_{k}+I_{e}\right)\right] .
$$

Since $M_{1}<M_{2}$, we can get $\Delta_{2} \geq \Delta_{3}>\Delta_{1}$ from equations (23)-(25). Summarized above arguments, the optimal cycle time $T^{*}$ and optimal payment time $\left(M_{1}\right.$ or $\left.M_{2}\right)$ can be obtained as follows.

Theorem 1 :

(A) If $\Delta_{1} \geq 0$, then $T R C\left(T^{*}\right)=\min \left\{T R C_{1}\left(T_{12} *\right), T R C_{2}\left(T_{23} *\right)\right\}$. Hence $T^{*}$ is $T_{12} *$ or $T_{23}{ }^{*}$, optimal payment time is $M_{1}$ or $M_{2}$ associated with the least cost.

(B) If $\Delta_{1}<0$ and $\Delta_{3}>0$, then $T R C\left(T^{*}\right)=\min \left\{T R C_{1}\left(T_{11}{ }^{*}\right), T R C_{2}\left(T_{23}{ }^{*}\right)\right\}$. Hence $T^{*}$ is $T_{11}{ }^{*}$ or $T_{23}{ }^{*}$, optimal payment time is $M_{1}$ or $M_{2}$ associated with the least cost.

(C) If $\Delta_{2}>0$ and $\Delta_{3} \leq 0$, then $T R C\left(T^{*}\right)=\min \left\{T R C_{1}\left(T_{11} *\right), T R C_{2}\left(T_{22} *\right)\right\}$. Hence $T^{*}$ is $T_{11}{ }^{*}$ or $T_{22}{ }^{*}$, optimal payment time is $M_{1}$ or $M_{2}$ associated with the least cost.

(D) If $\Delta_{2} \leq 0$, then $T R C\left(T^{*}\right)=\min \left\{T R C_{1}\left(T_{11} *\right), T R C_{2}\left(T_{21}^{*}\right)\right\}$. Hence $T^{*}$ is $T_{11} *$ or $T_{21}{ }^{*}$, optimal payment time is $M_{1}$ or $M_{2}$ associated with the least cost.

Theorem 1 immediately determines the optimal cycle time $T^{*}$ and optimal payment time $\left(M_{1}\right.$ or $\left.M_{2}\right)$ after computing the numbers $\Delta_{1}, \Delta_{2}$, and $\Delta_{3}$.

\section{NUMERICAL EXAMPLES}

To illustrate the theoretical results, let us apply the proposed method to solve the following numerical examples. The optimal solutions for different parameters of $\alpha, r$ and $c$ are shown in Table 1.The following inferences can be made based on Table 1.

(1). For fixed $r$ and $c$, the larger value of $\alpha$ is, the smaller value of the optimal cycle time and the higher value of the annual total relevant cost will be as the optimal payment time is $M_{2}$; however, if the optimal payment time is $M_{1}$, the optimal cycle time is independent of the value of $\alpha$.

(2). For fixed $\alpha$ and $c$, the larger the value of $r$ is, the larger value of the optimal 
cycle time and the lower value of the annual total relevant cost will be as the optimal payment time is $M_{1}$; however, if the optimal payment time is $M_{2}$, the optimal cycle time is independent of the value of $r$.

(3). And last, for fixed $\alpha$ and $r$, the larger the value of $c$ is, the smaller value of the optimal cycle time and the smaller value of the optimal order quantity will be.

Table 1. Optimal solutions under different parametric values

\begin{tabular}{|c|c|c|c|c|c|c|c|c|c|c|}
\hline \multicolumn{11}{|c|}{$\begin{array}{c}\text { Let } A=\$ 50 / \text { order, } D=1000 \text { units } / \text { year, } h=\$ 5 / \text { unit } / \text { year, } I k=\$ 0.15 / \$ / \text { year, } I e=\$ 0.12 / \$ / \text { year, } M_{1}=0.06 \text { year and } \\
M_{2}=0.12 \text { year. }\end{array}$} \\
\hline \multicolumn{11}{|r|}{ Optimal payment } \\
\hline \multirow[t]{9}{*}{0.1} & 0.005 & 10 & $<0$ & $>0$ & $<0$ & $2-(\mathrm{C})$ & $T_{22} *=0.12654$ & 126.5 & 10644.4 & $M_{2}$ \\
\hline & & 15 & $<0$ & $>0$ & $<0$ & $2-(C)$ & $T_{22} *=0.121$ & 121 & 15610 & $M_{2}$ \\
\hline & & 20 & $<0$ & $>0$ & $>0$ & 2-(B) & $T_{23} *=0.11601$ & 116 & 20574 & $M_{2}$ \\
\hline & 0.01 & 10 & $<0$ & $>0$ & $<0$ & $2-(\mathrm{C})$ & $T_{11} *=0.12481$ & 124.8 & 10620.6 & $M_{1}$ \\
\hline & & 15 & $<0$ & $>0$ & $<0$ & $2-(\mathrm{C})$ & $T_{11}{ }^{*}=0.11853$ & 118.5 & 15573.3 & $M_{1}$ \\
\hline & & 20 & $<0$ & $>0$ & $>0$ & 2-(B) & $T_{11} *=0.11316$ & 113.2 & 20524 & $M_{1}$ \\
\hline & 0.015 & 10 & $<0$ & $>0$ & $<0$ & $2-(\mathrm{C})$ & $T_{11} *=0.12487$ & 124.9 & 10570.6 & $M_{1}$ \\
\hline & & 15 & $<0$ & $>0$ & $<0$ & $2-(\mathrm{C})$ & $T_{11} *=0.1186$ & 118.6 & 15498.3 & $M_{1}$ \\
\hline & & 20 & $<0$ & $>0$ & $>0$ & 2-(B) & $T_{11} *=0.11323$ & 113.2 & 20424 & $M_{1}$ \\
\hline \multirow[t]{9}{*}{0.3} & 0.005 & 10 & $<0$ & $>0$ & $<0$ & $2-(\mathrm{C})$ & $T_{22}{ }^{*}=0.12539$ & 125.4 & 10652 & $M_{2}$ \\
\hline & & 15 & $<0$ & $>0$ & $>0$ & 2-(B) & $T_{23} *=0.1195$ & 119.5 & 15620.8 & $M_{2}$ \\
\hline & & 20 & $<0$ & $>0$ & $>0$ & 2-(B) & $T_{23} *=0.11418$ & 114.2 & 20587.8 & $M_{2}$ \\
\hline & 0.01 & 10 & $<0$ & $>0$ & $<0$ & $2-(C)$ & $T_{11} *=0.12481$ & 124.8 & 10620.6 & $M_{1}$ \\
\hline & & 15 & $<0$ & $>0$ & $>0$ & 2-(B) & $T_{11} *=0.11853$ & 118.5 & 15573.3 & $M_{1}$ \\
\hline & & 20 & $<0$ & $>0$ & $>0$ & $2-(\mathrm{B})$ & $T_{11}^{*}=0.11316$ & 113.2 & 20524 & $M_{1}$ \\
\hline & 0.015 & 10 & $<0$ & $>0$ & $<0$ & $2-(C)$ & $T_{11} *=0.12487$ & 124.9 & 10570.6 & $M_{1}$ \\
\hline & & 15 & $<0$ & $>0$ & $>0$ & 2-(B) & $T_{11} *=0.1186$ & 118.6 & 15498.3 & $M_{1}$ \\
\hline & & 20 & $<0$ & $>0$ & $>0$ & $2-(\mathrm{B})$ & $T_{11} *=0.11323$ & 113.2 & 20424 & $M_{1}$ \\
\hline \multirow[t]{9}{*}{0.5} & 0.005 & 10 & $<0$ & $>0$ & $<0$ & $2-(C)$ & $T_{22}{ }^{*}=0.12318$ & 123.2 & 10666.9 & $M_{2}$ \\
\hline & & 15 & $<0$ & $>0$ & $>0$ & 2-(B) & $T_{23} *=0.11654$ & 116.5 & 15642.1 & $M_{2}$ \\
\hline & & 20 & $<0$ & $>0$ & $>0$ & $2-(\mathrm{B})$ & $T_{23}{ }^{*}=0.11077$ & 110.8 & 20614.8 & $M_{2}$ \\
\hline & 0.01 & 10 & $<0$ & $>0$ & $<0$ & 2-(C) & $T_{11} *=0.12481$ & 124.8 & 10620.6 & $M_{1}$ \\
\hline & & 15 & $<0$ & $>0$ & $>0$ & 2-(B) & $T_{11} *=0.11853$ & 118.5 & 15573.3 & $M_{1}$ \\
\hline & & 20 & $<0$ & $>0$ & $>0$ & $2-(\mathrm{B})$ & $T_{11} *=0.11316$ & 113.2 & 20524 & $M_{1}$ \\
\hline & 0.015 & 10 & $<0$ & $>0$ & $<0$ & $2-(C)$ & $T_{11} *=0.12487$ & 124.9 & 10570.6 & $M_{1}$ \\
\hline & & 15 & $<0$ & $>0$ & $>0$ & 2-(B) & $T_{11} *=0.1186$ & 118.6 & 15498.3 & $M_{1}$ \\
\hline & & 20 & $<0$ & $>0$ & $>0$ & 2-(B) & $T_{11} *=0.11323$ & 113.2 & 20424 & $M_{1}$ \\
\hline
\end{tabular}

\section{CONCLUSIONS}

The supplier offers the permissible delay in payments to stimulate the demands of the retailer. But the supplier also hopes that the retailer can pay the payment as soon as possible. This paper investigates the retailer's replenishment and payment policy under supplier offered cash discount and permissible delay in payments depending on retailer payment time. The supplier can handle the fraction of the delay payment permitted and cash discount rate to attract the retailer to pay the payment as soon as possible to shorten the collection period. This policy is a valuable and realistic alternative to the supplier. Then, we develop the retailer's inventory model and provide a very efficient solution-finding procedure. Finally, numerical examples are given to illustrate the theoretical results. There are some managerial phenomena as follows: 
(1). When the fraction of the total amount owed payable is increasing, the retailer will order less quantity. Therefore, the supplier can use the higher fraction of permitted delay policy to stimulate the retailer's demands when the optimal payment time is $M_{2}$.

(2). When the cash discount rate is increasing, the retailer will adopt the optimal payment time in $M_{1}$ to shorten the delay period.

(3). When the unit purchasing price is increasing, the retailer will order less quantity to take the benefits of the permissible delay in payments more frequently whatever fully or partially permissible delay in payments.

In future research, we would like to extend to allow for shortages, deteriorating items or finite replenishment rate.

Acknowledgements- This paper is supported by CYUT.

\section{REFERENCES}

1. S.P. Aggarwal and C.K. Jaggi, Ordering policies of deteriorating items under permissible delay in payments. Journal of the Operational Research Society. 46, 658-662, 1995.

2. C.T. Chang, Extended economic order quantity model under cash discount and payment delay. International Journal of Information and Management Sciences. 13, 57-69, 2002.

3. C.T. Chang, L.Y. Ouyang and J.T. Teng, An EOQ model for deteriorating items under supplier credits linked to ordering quantity. Applied Mathematical Modelling. 27, 983-996, 2003.

4. K.J. Chung, A theorem on the determination of economic order quantity under conditions of permissible delay in payments. Computers and Operations Research. 25, 49-52, 1998.

5. K.J. Chung and Y.F. Huang, The optimal cycle time for EPQ inventory model under permissible delay in payments. International Journal of Production Economics. 84, 307-318, 2003.

6. K.J. Chung and J.J. Liao, Lot-sizing decisions under trade credit depending on the ordering quantity. Computers and Operations Research. 31, 909-928, 2004.

7. S.K. Goyal, Economic order quantity under conditions of permissible delay in payments. Journal of the Operational Research Society. 36, 335-338, 1985.

8. Y.F. Huang, Optimal retailer's ordering policies in the EOQ model under trade credit financing. Journal of the Operational Research Society. 54, 1011-1015, 2003.

9. Y.F. Huang, Optimal retailer's replenishment policy for the EPQ model under supplier's trade credit policy. Production Planning and Control. 15, 27-33, 2004.

10. Y.F. Huang and K.J. Chung, Optimal replenishment and payment policies in the EOQ model under cash discount and trade credit. Asia-Pacific Journal of Operational Research. 20, 177-190, 2003.

11. L.Y. Ouyang, M.S. Chen and K.W. Chuang, Economic order quantity model under cash discount and payment delay. International Journal of Information and Management Sciences. 13, 1-10, 2002.

12. J.T. Teng, On the economic order quantity under conditions of permissible delay in payments. Journal of the Operational Research Society. 53, 915-918, 2002. 